\title{
LA HERENCIA DE GUSTAVO GIOVANNONI: ESTUDIO DEL "CONSERVACIONISMO SINCRÉTICO” DE LEOPOLDO TORRES BALBÁS A TRAVÉS DE SU FACETA COMO HISTORIADOR DE LA ARQUITECTURA
}

\author{
BELÉN CALDERÓN ROCA \\ Universidad de Córdoba
}

\begin{abstract}
Resumen
Leopoldo Torres Balbás fue un importante artífice en el origen de una doctrina española sobre restauración arquitectónica. Del ámbito italiano y en concreto, de Gustavo Giovannoni, Torres Balbás heredó una particular forma de valorar la historia que le llevó a desarrollar un método sincrético para el estudio de la arquitectura, basado en el respeto de las singularidades de cada período y estilo que formaban parte de la fábrica histórica. En España, fue pionero en considerar el entorno de los monumentos como elemento digno de conservación, acometiendo intervenciones que perseguían la preservación del "carácter" del monumento, a la vez que su permanencia física en el tiempo.
\end{abstract}

\section{Palabras clave}

Leopoldo Torres Balbás, Gustavo Giovannoni, restauración arquitectónica, historia de la arquitectura, entorno.

\section{Abstract}

Leopoldo Torres Balbas was an important architect of the Spanish origin of a doctrine of architectural restoration. From the Italian area and the Gustavo Giovannoni's legacy, Torres Balbas undertook a particular appreciation of the history that led him to develop a syncretic approach to the study of architecture, based on respect for the singularities of each period and style that were part of the historic building. In Spain it was a pioneer in considered the environment of monuments worthy of preservation element, undertaking interventions to preserve the "character" of the monument, while its physical permanence in time.

\section{Keywords}

Leopoldo Torres Balbás, Gustavo Giovannoni, architectural restoration, architectural history, environment. 


\section{Introducción}

La figura de Leopoldo Torres Balbás debe analizarse necesariamente, desde una óptica poliédrica, abarcando sus facetas de arquitecto, historiador, crítico de arquitectura, así como representante de la restauración arquitectónica de una época, que aglutinó diferentes tendencias en su intento por configurar una doctrina española de la restauración, si bien, a nivel teórico. En 1916 obtuvo la titulación de arquitecto, y desde la Cátedra de Historia de la Arquitectura, cargo que ocupó en 1931, inició una intensa labor docente en la Escuela Superior de Arquitectura de Madrid (ESAM), ejerciendo magistralmente su carrera docente sobre Historia del Arte Español y Conservación de Monumentos, instrucción que nunca interrumpió. Su discípulo Fernando Chueca Goitia elogió su método didáctico, eminentemente pedagógico, pues Torres Balbás creía por encima de todo en la educación y en la regeneración del país por medio de la cultura. Además de instruir, educaba en la preocupación mayúscula por enseñar "a ver y a leer" la arquitectura a las generaciones de arquitectos de la ESAM durante tres décadas, basándose en la experimentación directa, la comparación y la extracción de reflexiones posteriores.

En sus inicios Leopoldo Torres Balbás se sintió profundamente inspirado por Giner de los Ríos y la Institución Libre de Enseñanza, que imprimieron en su pensamiento y actividad una aguda sensibilidad artística, espíritu crítico y ética profesional, bases sobre las que fundamentará su doctrina posterior y en la que incluirá dichas actitudes. Su labor investigadora sobre restauración monumental le condujo a ocupar en 1923 y durante trece años, el puesto de Arquitecto Conservador de la Alhambra y, asimismo, fue nombrado en 1929 Arquitecto Conservador de Monumentos Nacionales de la VI Zona. Estuvo pensionado en Italia en 1926 por la Junta de Ampliación de Estudios e Investigaciones Científicas, período fructífero que destinó al estudio de nuevos métodos y procedimientos para la conservación de monumentos, que le llevaría posteriormente a formular su decálogo sobre los diferentes tipos de intervención. Fue precisamente en Roma donde pudo sensibilizarse con los candentes debates sobre restauro que tenían lugar en la capital italiana por aquellos tiempos. La atribución a la arquitectura del valor histórico vinculado al valor de antigüedad, llegará a ser una constante en su trayectoria profesional como arquitectohistoriador-restaurador y se verá persuadido por la importancia histórica y estética de los edificios desaparecidos y desconocidos.

La prolífica trayectoria investigadora de Torres Balbás quedará plasmada en múltiples publicaciones, dejando constancia de ello revistas como Arquitectura, Archivo Español de Arte y Arqueología, Arte Español, Boletin de la Sociedad española de Excursiones, Boletín del Centro Artístico $y$ Reflejos de Granada, Andalucia, de Córdoba, o Annual Journal of the Gibraltar Society, de Gibraltar. A partir de los años cuarenta investigará casi exclusivamente sobre la arquitectura y el desarrollo urbano islámico, quedando reflejado en la revista $A l-A n d a l u s$, a través de la cual quedará patente la necesidad de extender la tutela desde los monumentos singulares a la realidad urbana en su conjunto.

La guerra civil ocasionó la destitución en 1936 de Torres Balbás como Arquitecto Conservador de la Alhambra y de la VI Zona, tras ser considerado simpatizante del frente popular ${ }^{1}$. Después de haber contemplado como se afianzaban sus ideas durante décadas, y tras el desgaste que supuso el empedernido debate sostenido durante los años veinte y treinta, el ostracismo social se tradujo en una ruptura forzosa en el campo disciplinar de la restauración. Finalizada la guerra, la gravedad de los daños puso en interrogación la conservación de las ruinas o su recuperación mediante la reconstrucción del patrimonio menoscabado y prevaleció la opción de no dejar obras "muertas", lo que proyectaría una imagen decadente y ruinosa de un país que se esforzaba por renacer. Tras su regreso obligado a Madrid, Torres Balbás se encuentra sometido a varios expedientes de depuración contra su persona, acusado de presuntas responsabilidades políticas en favor de la República entre 1936 y 1941. Y aunque no pudo probársele actividad política alguna, fue destituido de la Cátedra de Historia de la Arquitectura y Artes Plásticas, por orden de la Dirección General de

${ }^{1}$ VÍLCHEZ VÍLCHEZ, C.: Leopoldo Torres Balbás, Granada, Comares, 1999, p. 48 
Arquitectura $^{2}$. Llegado a este punto Leopoldo Torres Balbás se aísla para dedicarse a la investigación y aunque ya no se disfrutaban tiempos tan favorables para el debate, irá construyendo una historiografía que será determinante para el conocimiento de la teoría e historia de la arquitectura españolas.

\section{Influencia teórica de Gustavo Giovannoni en la práctica restauradora de Torres Balbás}

Inicialmente, Leopoldo Torres Balbás bebió de las fuentes de Camillo Sitte, Camillo Boito y Paul Leon, dedicándose con abnegada vocación a la búsqueda de criterios apropiados para las intervenciones en su práctica restauradora. Su contribución fue sustancial en la institución de un nuevo campo de pensamiento en materia de restauración, y sus múltiples investigaciones le condujeron a formular una teoría "renovada" basada en monumentos-tipo, ya que en este período nuestro país se encontraba muy a la cola en dichos aspectos respecto a otros europeos, como Italia o Francia. Durante las primeras décadas del siglo XX España era un país con múltiples y diversas culturas superpuestas, y la liberación de monumentos, especialmente de las catedrales, resultaba una práctica habitual como resultado de una arraigada tradición violletiana. Fiel a esta tendencia sobresalía la figura de Vicente Lampérez y Romea, quien abrigaba una fuerte vocación historiadora que le convirtió en el primer arquitecto español en formular un método concreto de actuación restauradora, mediante la sistematización de la historia de la arquitectura. Su labor investigadora unida a la praxis, completaría sus conocimientos históricos, definiendo un tipo de restauración que se traducirá en la reconstrucción del edificio en sus partes arruinadas o al borde de la ruina en su mismo estilo original ${ }^{3}$. Asimismo fue descubriendo nuevas parcelas en el método de estudio de la arquitectura hasta entonces desatendidas ${ }^{4}$. En la vertiente opuesta se situaba Ricardo Velázquez Bosco, adalid del conservacionismo y poseedor de grandes conocimientos arqueológicos. A través de su Cátedra de Historia de la Arquitectura y Dibujo de Conjuntos de la Escuela de Arquitectura de Madrid ${ }^{5}$, formó en estudios histórico-artísticos a un grupo de arquitectos del que sobresaldrá Leopoldo Torres Balbás, al que se le atribuirá el giro generacional que hará cambiar de rumbo el debate sobre restauración en España.

A pesar de no haberse asimilado todavía en nuestro país una visión urbanística global, ni tampoco encontrarse definido el concepto de entorno tal y como lo entendemos hoy, Torres Balbás fue manifiestamente contrario a la tendencia aislacionista ochocentesca de algunas catedrales europeas y españolas ${ }^{6}$. En el pensamiento de Torres Balbás se estableció la idea de que las catedrales no fueron concebidas para estar aisladas. Fueron proyectadas por sus artífices para ser contempladas desde corta distancia, y precisamente, las múltiples arquitecturas adyacentes constituían los elementos de referencia y comparación con aquéllas: "[...] a través de calles estrechas en cuyo fondo aparecían las puertas pobladas de un mundo

2 Expediente de responsabilidades políticas, fechado 31 de octubre de 1941. (A)rchivo (G)eneral de la (A)dministración, Sección Justicia, exp. n. 30541. Cfr. ESTEBAN CHAPAPRÍA, J:: "El expediente número 1652/1940 de responsabilidades políticas: proceso de depuración a Leopoldo Torres Balbás", en Papeles del Partal. Revista de Restauración Monumental, n.1, 2002, pp. 51-71

3 LAMPÉREZ Y ROMEA, V.: La restauración de los monumentos arquitectónicos. Teorías y aplicaciones, Madrid, Asocia-ción Española para el progreso de las Ciencias, Madrid, 1913

4 ORDIERES DÍEZ, I.: Historia de la restauración monumental en España (1835-1936), Madrid, Instituto de Conservación y Restauración de Bienes Culturales, Ministerio de Cultura, 1995, pp. 140-141.

5 Velázquez Bosco desarrolló trabajos vinculados a la administración pública. y cargos públicos como la restauración de la Capilla Real de Granada, Medina Azahara y la Mezquita de Córdoba. VELÁZQUEZ BOSCO, R.: Excavaciones en Medina Azahara: Memoria sobre lo descubierto en dichas excavaciones, Madrid, Imp. de la "Rev.de Arch., Bibl. y Museos", 1923.

6 Además de los ejemplos de París, Orleans y Colonia, señalamos algunas de las desafortunadas intervenciones de aislamiento en catedrales españolas como León, Burgos y Oviedo, en las que se actuó sustituyendo o simplemente, demoliendo el tejido urbano circundante. TORRES BALBẢS, L.: "El aislamiento de nuestras catedrales", en Arquitectura, II, Madrid, Órgano Oficial de la Sociedad Central de Arquitectos, diciembre, 1919, p. 358. 


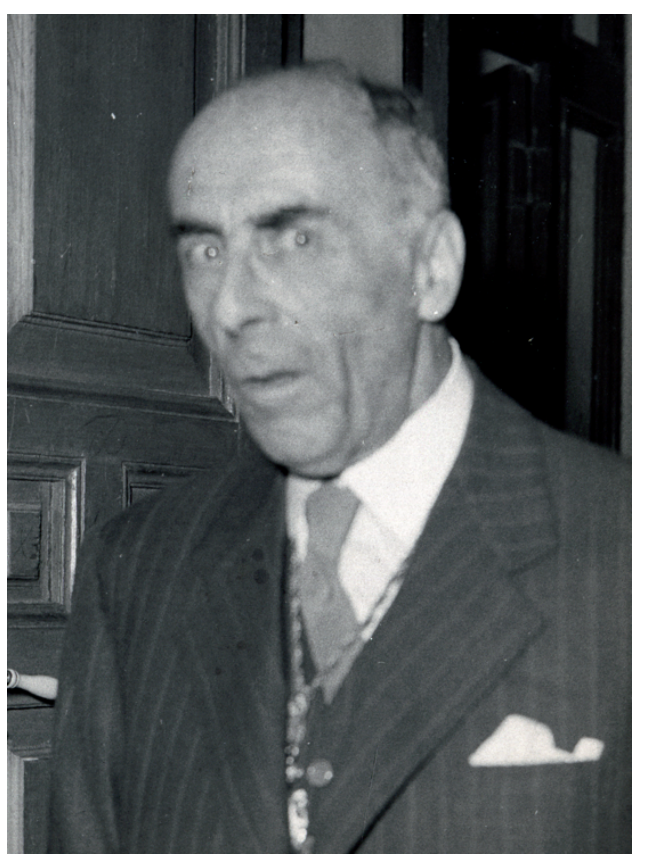

Fig. 1. Leopoldo Torres Balbás en 1958 ca. Foto: Archivo Fotográfico de la Real Academia Española de la Historia.

de figuras de piedra, las altas torres y los muros en perspectivas violentas [...] rodeada de otras construcciones mucho más modestas, contemplada desde el pie de sus muros, producía una impresión de esbeltez y verticalidad".

En su pensamiento, algunas restauraciones como las realizadas en las catedrales de Burgos o Toledo obedecían a una formación estética anacrónica y pseudoclásica, ausente de criterio moderno y fanática de una ciudad en estilo, motivada por la incapacidad para comprender la heterogeneidad del mapa patrimonial español: "El pueblo no entiende casi nunca de término medio, educado en el deseo de ver completamente aisladas las catedrales, creyendo que así parecerán más bellas $[\ldots]$ lo mismo que un paisaje $[. .$.$] si separamos una catedral de su$ ambiente secular aislándola, la convertimos en un monumento distinto" 8

Tras la concesión por la Junta de Ampliación de Estudios, de una pensión en la ciudad de Roma en 1926 por dos meses para investigar sobre las tendencias italianas en conservación monumental ${ }^{9}$, Torres Balbás comienza a frecuentar un clima de efervescencia cultural que, sin duda, le condujo a realizar un profundo estudio de la ciudad eterna ${ }^{10}$. A pesar de que la pensión concedida fue de dos meses, debido a las obligaciones oficiales de su cargo como Conservador de la Alhambra no pudo disfrutar del segundo mes de pensión, aunque ello no le impidió estudiar la obra de Gustavo Giovannoni :

En Roma púsose en comunicación con las personas oficialmente encargadas del servicio de excavaciones y bellas artes y con las interesadas en tales problemas, especialmente con don Adolfo Venturi, profesor de la Universidad de Roma y don Antonio Muñoz, subintendente de Monumentos y Bellas Artes del Lazio. Estudió detenidamente, sobre todo en su aspecto técnico de excavación, el foro y el Palatino, así como numerosos

7 Además de los ejemplos de París, Orleans y Colonia, señalamos algunas de las desafortunadas intervenciones de aislamiento en catedrales españolas como León, Burgos y Oviedo, en las que se actuó sustituyendo o simplemente, demoliendo el tejido urbano circundante. TORRES BALBÁS, L.: "El aislamiento de nuestras catedrales", en Arquitectura, II, Madrid, Órgano Oficial de la Sociedad Central de Arquitectos, diciembre, 1919, p. 358

8 TORRES BALBÁS, L.: Ibidem., p. 359.

${ }^{9}$ Real Orden 16-I-26. C., dos meses; D., un mes. -Italia-Estudiar los métodos y procedimientos para la conservación de los monumentos artísticos. Junta de Ampliación de Estudios (JAE), exp. Tores Balbás, sig.143-142

${ }^{10}$ Memoria presentada por Leopoldo Torres Balbás justificando la solicitud de su pensión en Roma, 1925. JAE, exp. Torres Balbás, sig.143-142. 
campos de ruinas de Roma, asistiendo asiduamente, merced a un permiso oficial, a las excavaciones del foro de Augusto, que por aquellos días se comenzaban, con el propósito de descubrir todos los restos imperiales, aún enterrados en el centro de la ciudad. Analizó las restauraciones de las iglesias de Santa María in Cosmedin, anterior a la guerra; Santa Sabina, recién ultimada, y San Giorgio in Velabro, en ejecución, visitando los trabajos de esta última en repetidas ocasiones y cambiando impresiones con su director y operarios que la realizaban. Estudió también la restauración del llamado Templo de la Fortuna Viril. El tiempo libre lo consagró a la visita de los restantes monumentos, museos y colecciones de Roma ${ }^{11}$.

Aunque no lo menciona de forma explícita, se deduce que Torres Balbás Balbás estuvo en contacto con los trabajos de rehabilitación que realizó Giovannoni en el Foro Boario ${ }^{12}$, con lo cual se podría constatar que en esta fecha mantuvieron contacto. Aunque quizás el procedimiento oficial para aproximarse al conocimiento de las intervenciones de restauro se realizara a través de Antonio Muñoz, Soprintendente de Arqueología. De lo que no cabe duda, es que viajar a Italia suponía para Torres Balbás establecer contacto con el ejemplo más auténtico de la tradición clásica, y se familiarizó inmediatamente con el tejido urbanístico romano. Observaba con entusiasmo en qué modo habían sido proyectadas las igle-sias, no de forma aislada, sino concebidas armonizando con su entorno, configurado por la arquitectura doméstica, tanto la destinada a servicios (capillas, sacristías o claustros), como por las viviendas que las rodeaban. Asimismo, supo asimilar de aquella atmósfera cultural cómo comenzaba a arraigarse la concepción del entorno, entendido como ambiente, y cómo la arquitectura vernácula era estudiada en sus múltiples parámetros: morfológicos, estructurales y estéticos. La comprensión y asimilación de la arquitectura religiosa y monumental incluía sus modificaciones, que iban sucediéndose con el paso del tiempo para armonizar con los edificios adyacentes. Las particulares condiciones de inserción de la arquitectura monumental en su entorno determinaban perspectivas caprichosas y exigían una contemplación forzosa a corta distancia, puesto que las construcciones de alrededor no permitían abarcar el conjunto desde puntos retirados, contribuyendo a enfatizar la verticalidad de las torres y la esbeltez de las portadas, así como el efecto de sorpresa que provocaba en el espectador.

Las constantes referencias de Torres Balbás a la ciudad de Roma ponen de manifiesto lo que en Francia ya se venía advirtiendo desde 1916: el riesgo que suponían las tendencias aislacionistas de los monumentos. Torres Balbás esgrime duros ataques contra la alteración de los entornos monumentales y censura duramente las intervenciones que propugna la Escuela Restauradora, la cual elude la inscripción del monumento en su trama urbana circundante: "Suprimir las construcciones adosadas a las catedrales es adulterar por completo la creación de los artistas medievales que las labraron [...] la belleza y el factor pintoresco que el tiempo ha ido prestando en una labor secular" ${ }^{\text {"13. }}$. Siempre defenderá la importancia de la arquitectura vernácula, instando a conservar su permanencia física en función de la preservación de su me-moria histórica, ante la posibilidad de insertarla en la vida contemporánea, como ya había apuntado Gustavo Giovannoni ${ }^{14}$. El histórico encuentro de ambos autores con motivo de la promulgación de la Carta de Atenas de 1931, fue la ocasión perfecta para que el historiador-arquitecto español representase a nuestro país en el debate ideológico acaecido en la ciudad eterna ${ }^{15}$. En dicho encuentro denunció públicamente las

\footnotetext{
${ }^{11}$ Memoria presentada por Torres Balbás a la vuelta de su estancia en Roma. "Memoria correspondiente a los cursos 1924-25 y 1925-26", JAE, Madrid, 1927, pp. 118-120. 530.

12 GIOVANNONI, G.: "La sistemazione del Foro Boario e del Velabro”, Capitolium, 9, 1926 (II), pp. 516-

13 TORRES BALBÁS, L.: Sobre monumentos y otros escritos... op. cit., p. 38

14 CALDERÓN ROCA, B.: La gestión de la ciudad histórica en la Roma fascista 1: la instrucción sobre restauro urbano a través de la obra de Gustavo Giovannoni”, en Boletín de Arte, n 28, Universidad de Málaga, 2007, pp. 253-277

15 N.B. Se constata la existencia de al menos tres cartas de Torres Balbás dirigidas a Gustavo Giovannoni en el Centro Studi per la Storia della Architettura (CSSAR), fondo Giovannoni, Roma. Por otra parte, el
} 
operaciones de restauración que falseaban por completo los monumentos y excluían los signos del paso del tiempo. Puesto que dichas huellas formaban parte de la historia de la arquitectura, con su pérdida se erradicaría su memoria histórica, desorientando e induciendo al error en su comprensión:

$[\ldots]$ en nombre de ese falso y desgraciado casticismo. Se nos quiso imponer el pastiche, y fijándose en las formas más exteriores de algunos edificios de esas épocas se las trasladó a nuestras modernas construcciones, creyendo así proseguir la interrumpida tradición de la raza ${ }^{16}$.

La esencia del texto citado se podría resumir en lo siguiente: la restauración que se acometía entonces, se basaba para Torres Balbás en estudios subjetivos y habitualmente rendidos a la equivocación. Éstos hacían perder el carácter de autenticidad del monumento y lo convertían en una reproducción del original, además de suponer siempre una obra muy costosa. Dichas afirmaciones cristalizarán en un maduro programa teórico elaborado tras su experiencia como Arquitecto Conservador al frente de la Alhambra y el Generalife desde $1923^{17}$. Cuando fue nombrado Arqutecto Conservador del monumento granadino, contaba con treinta y cinco años y ninguna experiencia práctica, si bien había desarrollado una gran actividad teórica. Sin embargo, el conjunto de obras de restauración realizada en Andalucía durante los años veinte y treinta, constituye su mayor contribución práctica como arquitecto restaurador. Aunque su actividad investigadora descendió durante el tiempo que le dedicó a las obras de la Alhambra, su actividad restauradora en cambio, fue intensa. Durante este período estudió exhaustivamente y sin descanso las fábricas del monumento, y periódicamente, transmitió los resultados de sus investigaciones y conclusiones a través de lecciones y conferencias en la ESAM.

En cualquier caso, en España durante esta época, al contrario de lo que sucedía en Italia, resulta casi imposible hablar de proyectos urbanos enfocados a la restauración, puesto que no podemos remitirnos más que a ejemplos de intervenciones aisladas. En este sentido Torres Balbás expresa abiertamente su crítica hacia la hermeticidad del panorama español en cuanto a las modernas tendencias de estética urbana desarrolladas en otros países europeos, como por ejemplo las propugnadas por Marcello Piacentini en Italia ${ }^{18}$, que resultaban en España demasiado desconocidas y evidenciaban las consecuencias en la praxis de los técnicos de la Administración, que permanecían anclados "a teorías estéticas anacrónicas". Sin embargo, durante toda su vida la voz de Leopoldo Torres Balbás se alzó duramente contra las tendencias urbanísticas de su tiempo, insistiendo en la utilidad de difundir y exponer el modo en el cual se iban destruyendo los monumentos españoles, que iba in crescendo ante la indiferencia del Estado y de la Iglesia, la incultura del pueblo y la desafortunada orientación de algunos arquitectos. Don Leopoldo no dudó en advertir del riesgo que suponía quedarse anclado en tendencias restauradoras obsoletas que respaldaban el aislamiento monumental, pues mediante la propensión hacia la apertura de plazas ante las fachadas de los monumentos, se acentuarían sus líneas horizontales y ofrecerían sensación de continuidad y monotonía, desvirtuándose y adulterando la concepción original de sus autores ${ }^{19}$.

Patronato de la Alhambra y el Generalife tras adquirir recientemente el archivo personal de Torres Balbás, ha mencionado la existencia de correspondencia entre éste y Gustavo Giovannoni. Noticia publicada en el diario El ideal, Granada, 28/06/2010.

16 ORRES BALBÁS, L.: “Mientras labran los sillares", en Arquitectura, I, junio, 1918, pp. 31-34.

17 DEZZI BARDESCHI, M.: 'L'Alhambra di Granada e i suoi 'restauri'. La 'fé antirestauradora' di Leopoldo Torres Balbás (1888-1960). Alla prova dei fatti”, en GALLEGO ROCA, J. [dir.]: Dos estudiosos, una cultura de la restauración arquitectónica: Piero Sanpaolesi y Leopoldo Torres Balbás (Seminario Torres Balbás, Granada, 2000), Granada, Universidad de Granada, Università degli Studi di Firenze, 2001, pp. 18-19.

18 CALDERÓN ROCA, B.: "La gestión de la ciudad histórica en la Roma fascista 2: urbanística, Piani Regolatori y conservación del patrimonio a través de la trayectoria de Marcello Piacentini”, en Boletín de Arte, no 28, Universidad de Málaga, 2007, pp. 279-306.

19 TORRES BALBÁS, L.: “El aislamiento...”, op. cit., p. 359. 
En su obra teórica, Torres Balbás aborda el problema de la ciudad y sus centros históricos de un modo claro y preciso; condenando duramente la postura proclive de los técnicos a la tendencia aislacionista y sosteniendo la exigencia de valorizar el monumento a partir de su significado urbano, es decir, incidiendo en la ineludible prioridad de conservar las arquitecturas que configuraban su inherente entorno. Con su posicionamiento intentó abrir camino al conocimiento de la arquitectura popular y a los monumentos desconocidos, a través de sus viajes de estudio por rincones inéditos de la geografía española. Asimismo, prosiguió su lucha por poner de relieve la necesidad de afrontar con nuevos métodos el problema de la restauración del patrimonio, planteando una reorganización de la Administración Estatal con respecto a los servicios encargados de su tutela, conservación y estudio.

Asimismo, es de sobra conocida la participación de Leopoldo Torres Balbás en numerosos congresos y reuniones científicas como la del $V$ Congreso Internacional del Turismo celebrado en 1912. En esta ocasión planteó la necesidad de atender a la riqueza artística del país como un medio para atraer al turismo, criticando ferozmente el desorden administrativo de su época y el riesgo que suponía la desaparición del patrimonio pintoresco que integraba el espíritu de los pueblos acumulado a lo largo de la historia. La alusión a los términos "artístico" y "turismo" parece obviar en un principio el componente histórico y nos obliga a interpretar el significado que lleva aparejado el término "pintoresco" en tales circunstancias. Para Torres Balbás, la destrucción de los monumentos y las ciudades, supone también la desaparición de gran parte de la esencia cultural de las sociedades (identificada con el espíritu nacional de los pueblos) que durante siglos han ido atesorando para goce y disfrute de las generaciones futuras: "(...) la supresión de todo elemento pintoresco ${ }^{20}$, el deseo de la uniformidad, el derribo de la calles estrechas, irregulares y viejas, y con frecuencia barrios enteros para hacer grandes avenidas y bulevares anchos y tirados a cordel (...) se trazan rectas calles a capricho sin preocuparse del relieve del suelo, cortando el corazón mismo de la ciudad antigua, derribando iglesias, palacios, edificios de todo género, interrumpiendo las circulaciones medievales" 21 . En esta cita el término "pintoresco" evidencia connotaciones plásticas y es utilizado como calificativo estético asociado a cuadros panorámicos o escenográficos. Podríamos identificar el término "pintoresco" utilizado por Torres Balbás, con aquellos paisajes dotados de un característico aspecto y singularmente atractivos a nivel estético. Por otra parte, Torres Balbás parece asociar el término "ciudad antigua" con la historia, y evocando a Azorín, reclama la imposibilidad de prescindir del pasado en su condición de testimonio irrecusable para el conocimiento de la arquitectura y, por supuesto, como material preciado para el historiador: “(...) no podremos conocer bien el presente conocer y amar- si no nos compenetramos de lo que hicieron y amaron nuestros antepasados"22.

Debemos tener en cuenta que por aquel entonces, lo antiguo y lo viejo eran prácticamente sinónimos de lo histórico y la connotación cultural que se evidencia cuando Torres Balbás hace alusión a la incultura de los ciudadanos, pretende aludir a la extensión espiritual que adquiere el acervo patrimonial acopiado a lo largo de los siglos. De este modo, valor histórico y valor cultural parecen integrarse en un término global: "patrimonio pintoresco". Aunque aún no aparezca acuñada una clara definición de ciudad histórica, sostenemos que Torres Balbás parece referirse con dicha expresión al patrimonio construido de la ciudad en su zona de mayor estratificación histórica (casco antiguo) es decir, al conjunto de elementos

\footnotetext{
${ }^{20}$ Todos los subrayados del texto son nuestros

21 TORRES BALBÁS, L.: "Los monumentos históricos y artísticos: destrucción y conservación. Legislación y organización de sus servicios y su inventario" (ponencia presentada en el VIII Congreso Nacional de Arquitectos, Zaragoza 30 septiembre-7 octubre, 1919), en Cuadernos de restauración, n. V, Instituto Juan de Herrera, ETSAM, 1999, pp. 36-37

22 AZORÍN: "El paisaje en las letras clásicas", en El paisaje de España visto por los españoles, Madrid, Renacimiento, 1912. Cfr. TORRES BALBÁS, L.: "La enseñanza de la historia de la arquitectura", en Arquitectura, V, febrero, 1923, p. 36.
} 
Situación primitiva.
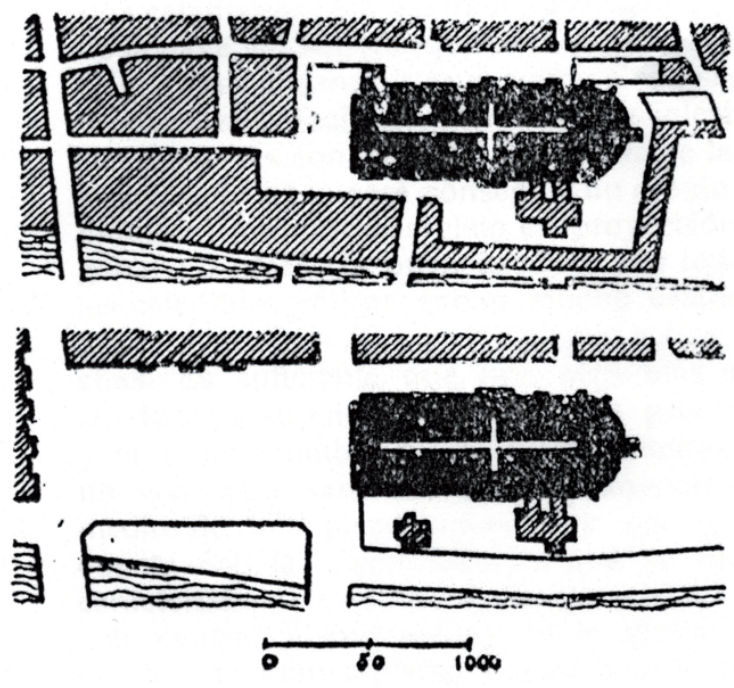

Situación actual. PARÍS.-EMPLAZAMIENTO DE NUESTRA SEÑORA.

Fig.2. Catedral de Notre-Dame y su entorno, antes y después de su aislamiento.

heredados depositarios de unos valores que ofrecen información sobre hechos o acontecimientos extrínsecos a ellos mismos, configurando un paisaje complejo del que forman parte piezas materiales y testimoniales, estéticas, sociológicas y etnológicas.

En lo que respecta a este trabajo, nos interesa especialmente, la creencia arraigada en Leopoldo Torres Balbás, sobre la pérdida irreparable que suponían las lesiones a la arquitectura histórica como documentos de trabajo para el historiador, puesto que únicamente serían útiles a la historia mientras conservasen su integridad y autenticidad. Nuestro protagonista analiza con vehemencia y sumo empeño la antinomia existente entre creatividad e historia; entre la conservación y la renovación en el contexto de los profesionales dedicados a la restauración: "Combato ideas y procedimientos como consecuencia de una íntima convicción fuertemente arraigada" ${ }^{23}$. Precisamente, fue esta realidad la que le impulsó a interesarse por la historiografía arquitectónica y a desdeñar en cierto modo, el ejercicio profesional creativo. Don Leopoldo se introduce en el campo de la historia del arte, concretamente en el de la historia de la arquitectura, deteniéndose en la necesidad de la multidisciplinariedad, realizando un estudio de los edificios que parte de una nueva visión positivista, comparando los monumentos mediante su clasificación tipológica y continuar en cierto modo, la ruta abierta en la historiografía española por Vicente Lampérez y Romea, si bien con otros matices. La línea teórica de Torres Balbás continuó hacia el respeto absoluto por la historia del monumento; un respeto que no afectaba únicamente a la imagen física de las fábricas, tal y cómo se manifestaba en el presente, sino que abarcaba la conservación de aquél como un documento capaz de ofrecer testimonios sobre datos o acontecimientos históricos. Y como Giovannoni, Torres Balbás iniciaba sus estudios partiendo del edificio aislado para extenderse en ocasiones hasta el conjunto urbano, antecedentes de lo que más tarde constituirán sus investigaciones sobre urbanismo histórico.

Es más que destacada su contribución al VIII Congreso Nacional de Arquitectos celebrado en Zaragoza en $1919^{24}$, ocasión en la que Torres Balbás expone el problema fundamental que afectaba al patrimonio monumental español: la desidia ante su conservación

${ }^{23}$ TORRES BALBÁS, L.: "Los monumentos históricos y artísticos”, op. cit., p. 35.

${ }^{24}$ ISAC, A.: "La ponencia de D. Leopoldo Torres Balbás en el VIII Congreso Nacional de Arquitectos de 1919”, en Cuader-nos de Arte, Departamento de Historia del Arte, Universidad de Granada, n. XX, 1989, pp. 195-210. 


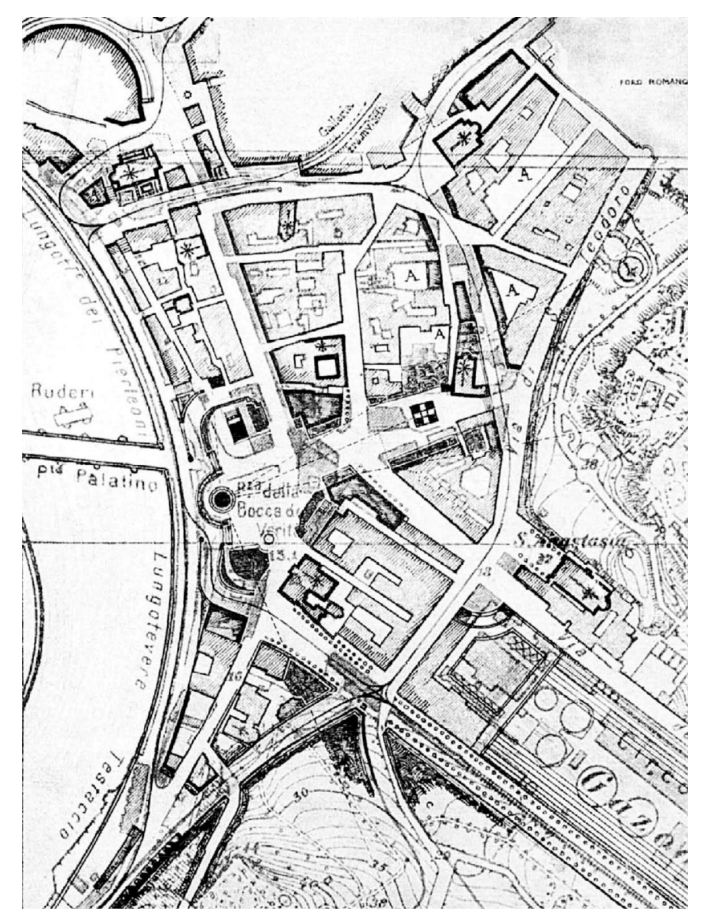

Fig.3a. Zona del Foro Boario antes de la apertura de la Via del Mare. Área de excavación y demoliciones previstas. Planimetría de Gustavo Giovannoni, $1925 . \quad$ Foto: GIOVANNONI, G.: "La sistemazione del Foro Boario e del Velabro", Capitolium, 9, 1926 (II).

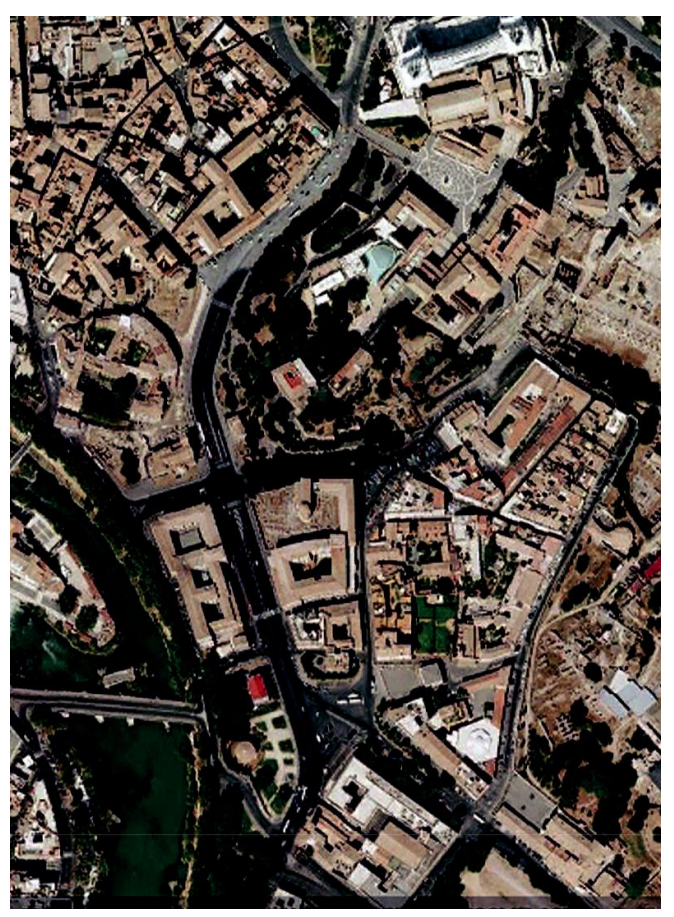

Fig.3b. Zona del Foro Boario en la actualidad, con la plaza de Santa María in Cosmedin y la gran avenida de la Via del Teatro Marcello (antigua Via del Mare). Foto: Google Earth.

y el desconocimiento de medios para afrontarla. Se remite a los libros de viajes en los que se retrata la memoria del acervo monumental lacerado y perdido, que supone la desaparición de gran parte de la historia española. Asimismo, critica ferozmente la ignorancia de las corporaciones locales en su afán por llevar a término los ensanches demandados por las nuevas ciudades, suprimiendo todo elemento histórico y pintoresco de la ciudad antigua, calles estrechas, adarves, placetas..., que deben ceder obligatoriamente a la piqueta ante el deseo de uniformidad urbanística y ante la construcción de grandes avenidas y bulevares: "En su labor destructora encuentran los ayuntamientos muchas veces apoyo en la incultura de los ciudadanos y en menguados intereses políticos (...) Esperemos que el progreso de la educación pública modifique los proyectos bárbaros de los municipios" ${ }^{25}$. Con su contribución, Leopoldo Torres Balbás comprobaría como sus pretensiones se verían recompensadas, quedando plasmados los resultados de sus investigaciones sin pretenderlo, en lo que sería el sustrato de la primera ley moderna en materia de tutela del patrimonio en España: la Propuesta de Ley de 1932 sobre la Protección del Tesoro Artístico Nacional ${ }^{26}$, que supondrá la superación por los poderes públicos del anterior debate con la promulgación de la Ley del Tesoro Artístico Nacional de 1933.

Pero remitámonos de nuevo a la propuesta de ley. Este documento respondió perfectamente a los planteamientos contenidos en la Carta de Atenas, de la que Torres Balbás

25 TORRES BALBÁS, L.: "Los monumentos históricos y artísticos”, op. cit., p. 39.

26 Propuesta de Ley sobre la Protección del Tesoro Artístico Nacional 12 de marzo de 1932, presentada a las Cortes Consti-tuyentes por el Ministro de Instrucción Pública y Bellas Artes Fernando de los Ríos Urruti. (Gaceta de Madrid, n. 94, con fecha 03-04-1932), pp. 122-126. 
fue un magnífico exponente ${ }^{27}$. Coincidiendo con el pensamiento de Giovannoni y Adolfo Venturi, Torres Balbás expuso con su participación los fundamentos del criterio moderno de la restauración, sustentado en un respeto escrupuloso de la memoria histórica (en aquella época "riqueza o recuerdos" histórico-artísticos) constituida por todas las estratificaciones presentes en la arquitectura. Torres Balbás reconocía la ineficacia de la legislación anterior y advirtió que la conservación constituía una empresa de utilidad pública y como tal, urgía la promulgación de medi-as administrativas y legislativas que pudiesen garantizar la tutela de los bienes en beneficio de la colectividad, evitando de este modo su destrucción o emigración ${ }^{28}$. Asimismo, aconsejaba realizar labores necesarias para su conservación, atendiendo al estado actual del edificio, tal y como había sido trasmitido hasta la fecha. Las actuaciones debían estar encaminadas a la preservación de su primitiva estructura y aspecto, con el objeto de facilitar el acceso y el estudio tanto a las generaciones coetáneas como posteriores, porque "un monumento antiguo es, en muy contadas ocasiones, de un mismo estilo en todas sus partes. Ha vivido y viviendo se ha transformado. Porque el cambio es la condición esencial de la vida. Cada edad lo ha ido marcando con su huella. Es un libro sobre el cual cada generación ha escrito una página. No hay que modificar ninguna de ellas. No son de la misma escritura porque no son de la misma mano" ${ }^{\text {"29. }}$. Asimismo, puso de relieve la exigencia de fundar un cuerpo especializado de arquitectos conservadores; un organismo verdaderamente técnico y competente en conservación de monumentos, integrado por especialistas dotados de sólidos conocimientos científicos, que pudiesen aplicar con éxito los procedimientos del restauro moderno.

En el Congreso de Historia del Arte, celebrado en París del 26 de septiembre al 5 de octubre de $1921^{30}$, Torres Balbás se había mostrado entusiasmado con su primera toma de contacto con "el ilustre Sr. (Adolfo) Venturi" y otros prestigiosos historiadores del arte europeos como Paul Leon. El arquitecto español contribuye en una sección sobre restauraciones de monumentos con su comunicación: "Inventario y clasificación de los monasterios cistercienses españoles", en la cual aborda la discusión sobre cómo afrontar los problemas derivados de la conservación de los monumentos afectados por la primera guerra mundial. Las exposiciones teóricas fueron contrastadas a través de visitas técnicas realizadas en las excursiones, donde se pudieron comprobar los criterios de actuación adoptados en la praxis de la restauración en Francia. A pesar de no ser un congreso dedicado al tema de la restauración monumental, Torres Balbás subraya la importancia que se concede en el evento a dicho tema, pues incluso se alude a la necesidad de celebrar un congreso internacional para tratar aspectos específicos sobre este asunto. Consideraba prioritario convocar una reunión científica que pudiese aglutinar a especialistas de diversas disciplinas como historiadores del arte, arqueólogos, artistas, coleccionistas, restauradores, químicos o juristas, para que con su "especial competencia puedan aclarar cuestiones tan complejas" ${ }^{31}$. ¿Sería quizás este congreso la antesala de la conferencia de Atenas?

No podemos responder con certeza a esta pregunta, pero es curioso que diez años más tarde tuviese lugar un importante acontecimiento que marcará sin duda, un punto de inflexión en la historia y teoría de la restauración española y Leopoldo Torres Balbás será partícipe. El arquitecto formará parte de la Delegación Española en la Conferencia de Atenas presentando un trabajo bajo el título "Evolución del criterio respecto a la restauración de monumentos en la España actual", que fue publicado en lengua francesa en la revista Musseion de 1932 y ampliado en 1933 en la revista Arquitectura, con el título "La reparación de los

${ }_{27}^{27}$ MUÑOZ COSME, A.: La vida y obra de Leopoldo Torres Balbás, Sevilla, Consejería de Cultura de la Junta de Andalucía, IAPH, 2005, p. 121

28 Propuesta de Ley Sobre la Protección del Tesoro Artístico Nacional de 1932, cit., Exposición de Motivos

${ }^{29}$ ISAC, A.: "La ponencia de D. Leopoldo Torres Balbás...", op. cit., p. 201

30 TORRES BALBÁS, L.: "El Congreso de Historia del Arte (París, septiembre-octubre 1921)", en Arquitectura, IV, enero, 1922, pp. 3-21.

${ }^{31}$ Ibidem., pp. 9-10. 


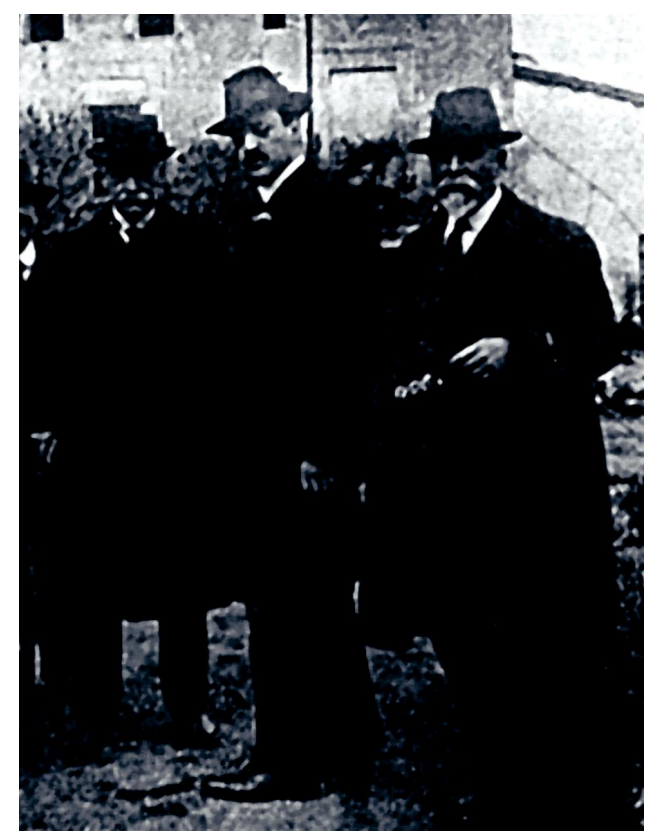

Fig.4. Gustavo Giovannoni, Antonio Muñoz y Corrado Ricci en la iglesia de Santa Sabina, Roma, 1930 ca. Foto: Archivio Generale Ordine dei Padri Predicatori.

monumentos antiguos en España"32. En este artículo Torres Balbás nos ofrece una aproximación a la teoría de la conservación-restauración arquitectónica en España desde su visión personal del problema, que se revela como un acto de reflexión condicionado por el influjo de la doctrina giovannoniana. Asimismo, pone de relieve su reconocimiento a la figura de Francisco Giner de los Ríos, su maestro, que influirá notablemente en su valoración de la historia y la estética de los monumentos a través de las visitas y excursiones ${ }^{33}$.

El extracto del texto que Torres Balbás presentó en la Conferencia de Atenas, fue resultado de una profunda reflexión personal en torno al problema de la restauración tal y como había sido entendida hasta la fecha. Sus conclusiones, emitidas en el citado congreso, quedarán codificadas en un decálogo sobre la definición de los diferentes tipos de intervención en los monumentos, así como su pertinente elección para cada caso concreto:

Restaurar un monumento antiguo es rehacer lo que de él ha sido destruido o se encuentra en mal estado de conservación, con arreglo a la forma que tuvo o debió tener primitivamente.

Reparar es conservarlo tal y como ha llegado hasta nuestros días, limitándose (en casos únicamente necesarios) a sustituir las partes desaparecidas por otras que hagan fácilmente identificable los materiales modernos implantados.

Consolidar es reducir la intervención en un monumento al mantenimiento de las partes existentes, sin reemplazar ningún fragmento por deteriorado que esté. La consolidación es siempre la postura ideal de máximo respeto al carácter de autenticidad del monumento, si bien la reparación es justificable en bastantes casos, aunque no mediante un criterio metodológico universal. Es decir, las actuaciones habrán de partir de un estudio exhaustivo e individual de cada caso concreto, y la puesta en práctica de los criterios de intervención se llevará a cabo con la máxima cautela ${ }^{34}$.

${ }^{32}$ La comunicación presentada en la Conferencia Internacional de Atenas fue publicada por Torres Balbás tres años más tarde, compilada en una serie de tres artículos correlativos en la revista Arquitectura (I, enero 1933, pp. 1-10), (II, mayo 1933, pp. 129-135) y (III, agosto 1933, pp. 213-223).

33 GONZÁLEZ HERNÁNDEZ, A.: "Leopoldo Torres Balbás: sobre monumentos y otros escritos", en GALLEGO ROCA, J. [dir.]: op. cit., pp. 68-69

34 TORRES BALBÁS, L.: "La reparación de los monumentos antiguos en España I", en Arquitectura, enero, 1933 , p. 1 
En España se estaba comenzando a implantar una nueva consideración del monumento que rompía con las prácticas anteriores y ya no debía diferenciar éste de su trama urbana adyacente, con quien precisamente debía continuar manteniendo una relación dialéctica de suma importancia. La conservación de la ciudad histórica y la protección del ambiente original de los trazados históricos, fueron fruto de una reflexión contemporánea que superó la imagen limitada del monumento hasta llegar a un proyecto más amplio y dinámico que se integraba en una compleja realidad, de la cual, el monumento constituía el componente fundamental. Estas orientaciones condujeron a Torres Balbás a estudiar a Giovannoni como figura que teorizaba tal apertura del monumento y lo colocaba en manifiesto diálogo con la ciudad histórica. De sus contactos con el arquitecto italiano en Roma se impone en España la noción de insieme storico y se articulan inmediatamente algunos instrumentos de protección legal y urbanística de los ambientes monumentales. En realidad, las observaciones de Torres Balbás constituyen una repetición abreviada de las tesis de Camillo Sitte con algunos sincretismos, que asimilan las particularidades del entorno español. No obstante, la influencia de Gustavo Giovannoni en Leopoldo Torres Balbás resulta evidente, pues se observan trazas de sus enseñanzas sobre la inconveniencia de aislar los monumentos, indisociables de su trama urbana circundante, que los articula, argumenta y preside ${ }^{35}$.

Incide en las ventajas que se derivan de la conservación de las estructuras y disposición original de la arquitectura doméstica tradicional (a nivel histórico y urbanístico), razonando que los monumentos resultan más interesantes si se contemplan desde perspectivas oblicuas, direccionadas por la concepción original de su autor y rodeadas de construcciones más modestas que dan sensación de grandeza y verticalidad. En honor a la verdad, las catedrales fueron construidas de este modo, teniendo en cuenta dichas circunstancias. Por el contrario, con su aislamiento se eliminaban estas perspectivas y el panorama viraba hacia el dominio de las líneas horizontales. La obtención de "perspectivas relativas" que rediseñan el ambiente a modo escenográfico, en opinión de Torres Balbás, no serviría más que para sacrificar ejemplos arquitectónicos dotados de valor y constreñir las catedrales a perspectivas unidireccionales, forzando su contemplación como si de cuadros de un museo se tratasen. En suma, el fundamento de la teoría de Torres Balbás era la valorización consciente del ambiente, del entorno en el cual estos edificios estaban insertos: "cada obra de arte está concebida para vivir en un cierto ambiente, si se modifica éste, le quitamos un parte muy importante de su calidad". ${ }^{36}$

Como sucedía con Gustavo Giovannoni, Leopoldo Torres Balbás fue fundamentalmente un teórico. Este paralelismo justifica que muchos de los temas y puntos de vista que profesaba el español mantengan analogías con la línea seguida por Giovannoni en Italia ${ }^{37}$. Si el italiano se oponía a las tendencias urbanísticas de su tiempo y censuraba la reclusión de los monumentos en reductos aislados, el español condenaba el aislamiento de las catedrales; postura que se convirtió en una de sus principales preocupaciones en sus últimos años. Era ineludible pasar del caso aislado a la reconstitución del ambiente de las ciudades, tal y como él mismo declara en el siguiente texto: "Los viejos edificios, más o menos alterados por el paso de los siglos (...) no son más que islotes, testimonios aislados de civilizaciones desaparecidas. Para intentar comprenderlos, es necesario evocar el ambiente en el que se

35 CACCIAVILLANI, C. A.: "Joan Rubió Bellver, Leopoldo Torres Balbás, Jerónimo Arroyo López e il pensiero di Gustavo Giovannoni in Spagna", en SETTE, M. P. [a cura di]: Gustavo Giovannoni: Reflessioni agli albori del XXI secolo. Giornata di Studio dedicata a Gaetano Miarelli Mariani (1928-2002), Roma, Bonsignori Editore, 2005, p. 152 117

${ }^{36}$ CALAMA, J. M. y GARCÍA, A. G.: La restauración monumental en España, de 1900 a 1936, Sevilla, 2000, p.

37 CALDERÓN ROCA, B.: "La tutela de la ciudad histórica durante los períodos autárquicos: Gustavo Giovannoni (1873-1947) y Leopoldo Torres Balbás (1888-1960) ante la cuestión historiográfica", en Actas de la III Bienal de Restauración Monumental. Sobre la desrestauración (Sevilla, 23-25 de noviembre de 2006), Sevilla, Junta de Andalucía, Consejería deCultura, 2008, pp. 147-157 
levantaron, reconstruir idealmente el medio capaz de crearlos y el conjunto urbano del que formaron parte" 38 .

La teoría española en esa fecha trataba de apostarse en el ambiente de ebullición cultural europeo de la mano de la Junta para la Ampliación de Estudios e Investigaciones Científicas y en el campo del patrimonio en concreto, a través del Centro de Estudios Históricos. Torres Balbás fue enviado a participar en la Conferencia de Atenas en la Sección: "Doctrinas y Principios Generales" junto a Giovannoni, para dar a conocer fuera de nuestras fronteras los avances que en materia de patrimonio se habían producido en España, respecto a las medidas políticas adoptadas y el establecimiento de los órganos políticos, consultivos y técnicos, en concreto con la creación del cuerpo de arquitectos conservadores: “(...) lo único útil y sensato es fijar una orientación general, y ésta creemos que debe ser la del máximo respeto a la obra antigua, conservando las fases y adiciones posteriores que tengan interés histórico, arqueológico, artístico o monumental, huyendo lo más posible de añadir lo nuevo y diferenciando siempre lo añadido, para que nunca pueda confundirse con la obra antigua, al mismo tiempo que se procura atender al ambiente ${ }^{39}$.

El mensaje que tratará de ofrecer Torres Balbás será su oposición a la manipulación del monumento en su condición de documento histórico (su valor primordial) lo que debe mucho a los postulados de Camillo Boito y Gustavo Giovannoni, aunque en muchas ocasiones se quede anclado únicamente en la teoría. No obstante, el corpus ideológico de Torres Balbás ya había sido delineado algunos años antes, declarándose a favor de los materiales modernos siempre que se pudiese verificar las diferencias entre la obra original y la nueva intervención. Su contribución a la Conferencia de Atenas puede sintetizarse en la elaboración de un maduro programa teórico, en el que aparece digerido un conservacionismo ecléctico, extraído y determinado por las dificultades que se le plantearon cuando se enfrentó a la restauración de la Alhambra ${ }^{40}$ : "cada viejo edificio presenta un problema diferente y debe ser tratado de distinta manera" 41 .

En las obras del monumento granadino aplicó su particular fórmula científica, continuando los postulados de Velázquez Bosco de respeto absoluto a las ruinas ${ }^{42}$ y optando por la consolidación antes que por la restauración: “(...) abandonar las restituciones integrales y a evitar sus riesgos mediante la institución de obras de mantenimiento regular y permanente (...) respetar la obra histórica y artística del pasado, sin menospreciar el estilo de ninguna época" "43. Torres Balbás asimiló y reelaboró los problemas de la Alhambra notablemente, apostando por el mantenimiento del valor histórico-arqueológico (de antigüedad) residente en sus formas artísticas. Comprendió que la restauración participaba, necesariamente, del criterio histórográfico como factor preliminar, no sólo para el conocimiento de los materiales, procedimientos, usos, atribución estilística o autoría, sino fundamentalmente, para establecer una orientación correcta del estudio de las relaciones entre el monumento, su entorno y la mano del arquitecto restaurador.

La asimilación de la necesidad de conciliar el criterio histórico con el análisis visual de las fábricas, le permitió elaborar una metodología de interpretación del monumento aplicable al monumento granadino a nivel teórico. Giovannoni aportará a Torres Balbás un nuevo modo de entender la restauración que quedará patente en la Carta de Atenas, mediante el compromiso de conservar y abandonar las restituciones integrales, efectuando restauraciones

\footnotetext{
38 TORRES BALBÁS, L.: Algunos aspectos del mudejarismo urbano medieval”, Discurso de ingreso en la Real Academia de la Historia, Madrid, 1954

${ }^{39}$ Extraído de la comunicación de Torres Balbás en la Conferencia de Atenas. Cfr. TORRES BALBÁS, L.: "La reparación... op. cit. 9

${ }^{40}$ GALLEGO ROCA, J.: "Leopoldo Torres Balbás y Piero Sanpaolesi: Dos estudiosos, una cultura de la restauración arqui-tectónica", en GALLEGO ROCA, J. [dir.]: op. cit., pp. 9-10.

41 TORRES BALBÁS, L.: "La Alhambra y su conservación”, en Arte Español, XVI, T. VIII, Madrid, 1927.

42 VÍLCHEZ VÍLCHEZ, C.: "El Plan General de Conservación de la Alhambra de Ricardo Velázquez Bosco", Cuadernos de la Alhambra, n. 26, Granada, 1990, pp. 249-264.

${ }^{43}$ Carta de Atenas, 1931, art. 2.
} 


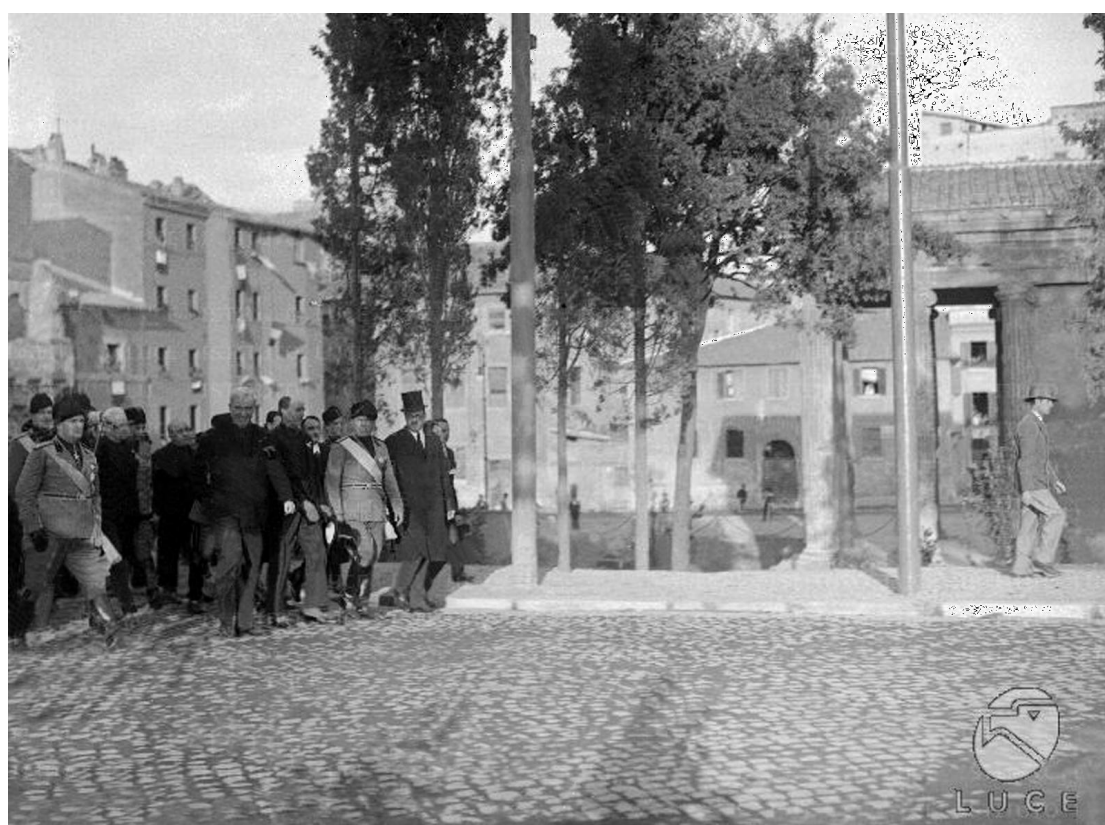

Fig.5 Visita a las excavaciones en el Foro Boario y zona de la Boca de la Verdad, Roma. Entre otras autoridades, Mussolini aparece en el centro y a su izquierda, Antonio Muñoz con sombrero, 28-10-1930. Foto: ASIL, no A00025246.

que debían participar de la necesidad de conocimiento de técnicas, materiales y territorios. La proposición de nuevos de tipos de intervención oscilantes entre la consolidación y la renovación, permitirían utilizar materiales modernos y reconocibles.

Con su participación en la Conferencia de Atenas, también se evidencia en Torres Balbás la asimilación del principio ético propugnado por Giner de Ríos sobre la adulteración de las obras de arte antiguas y la importancia que este último concede al criterio histórico, quien denuncia las restauraciones que falseaban por completo el monumento, condenándolo a una imagen abstracta y desprovista de vida ${ }^{44}$.

\section{Delineación del concepto "conservacionismo sincrético"}

Hemos acuñado el concepto Conservacionismo Sincrético para designar los preceptos que formula Torres Balbás para afrontar la tutela de la arquitectura histórica. Sería más acertado afirmar que se trata de una nueva corriente de pensamiento, más que de una doctrina, cuyo criterio se basa en una sensibilidad inusitada proyectada en las intervenciones sobre la arquitectura histórica, optando por el racionalismo, en vez de continuar con los presupuestos historicistas eclécticos habituales. Dicha corriente se orienta fundamentalmente, a procurar la preservación del "carácter" del monumento y el máximo respeto hacia la obra antigua y la totalidad de las partes del mismo. Dicho de otro modo, se contempla la consolidación, el mantenimiento y la prolongación de la vida física del monumento sin privarlo de autenticidad, es decir, evitando actuaciones exclusivistas que antepongan el criterio particular de cada técnico, tratando de crear un ambiente de colaboración que anticipa la interdisciplinaridad. El conservacionismo sincrético, excluye por tanto, la unicidad del método y el dogmatismo en las intervenciones, afrontando cada experiencia desde el máximo

${ }^{44}$ GALLEGO ROCA, J.: “Leopoldo Torres Balbás y Piero Sanpaolesi... op. cit., p. 10. 
respeto hacia la obra original, así como a los aspectos concretos de cada fase y estilo que forman parte de la fábrica histórica: "La restauración o reconstruc-ción [...] falsea por completo los monumentos que la padecen. Trata de borrar la acción del tiempo que ha ido añadiendo a cada antigua construcción, obras a veces de gran interés y belleza, para darle un aspecto teórico, abstracto, desprovisto de vida. Intenta engañar, prestando a los elementos añadidos, que no pueden tener nunca el mismo valor que los antiguos, formas semejantes a éstos, desorientando e induciendo al error [...] se basa sobre estudios personales, siempre discutibles y sometidos con gran frecuencia al error. Hace perder su carácter de autenticidad al monumento" 45 .

Otro aspecto innovador del pensamiento de Leopoldo Torres Balbás es el val-or que concede a la funcionalidad de la intervención, justificación y mérito del proyecto en sí mismo: "Procuremos que cada edificio, en lo posible, siga adscrito al mismo destino para el que se construyó. Y cuando tal cosa no sea posible, démos-les un destino de movimiento y animación en el que sus puertas y ventanas estén siempre abiertas [...] a toda la intensidad de nuestra vida actual" " ${ }^{\prime 6}$. En la defensa del potencial valor de uso atribuido a los conjuntos urbanos, Torres Balbás plantea el estudio historiográfico como mecanismo para acceder a una correcta reutilización de las estructuras históricas. Defiende la adecuación de éstas al presente pues, en pocas ocasiones, la vida moderna debe encontrarse en conflicto con la conservación

de los viejos edificios; se trata de conciliar ambos intereses. De las siguientes pal-abras, deducimos la permeabilidad de sus teorías a los contactos con el ámbito ital-iano, en concreto, al riuso atribuido a los conjuntos urbanos por Giovannoni: "Un edificio se ha hecho para ser habitado por el hombre o por la divinidad. No puede decirse lo mismo cuando lo visitamos de tarde en tarde, como se visita un museo, que cuando con él está mezclada parte de nuestra vida" ${ }^{\prime 7}$.

Caracteriza sin duda a Torres Balbás, a nivel teórico, una visión moderna de línea crítica, en una sociedad donde los edificios y los centros históricos comienzan a asumir el papel de patrimonio, es decir, de un bien público social y cultural, de herencia. Así pues, se inaugura en el ámbito español, si bien sucintamente, el concepto de ambiente, que él denomina "aspecto artístico del edificio" y que podemos asimilar con el entorno de los monumentos.

Fernando Chueca Goitia sostenía que Leopoldo Torres Balbás era un especialista en historia de la arquitectura dotado de rigor científico y aguda sensibilidad estética, aunque debiese ceñirse a un campo de acción muy limitado. Su condición eminen-temente medievalista pudo influir posiblemente en la aplicación de su particular modo de concebir el valor histórico con una inflexibilidad extrema, valor que se remitía en última instancia al de antigüedad $^{48}$. No obstante, en la praxis, Chueca afirmaba que el criterio práctico de Torres Balbás se basaba en "completar sin de-struir, añadir sin restar, recrear el compendio del monumento revivido sin ruptura ni falsificación, en su más pura esencia"49. Su discípulo declaraba, que si al hacerse cargo de obras como la Alhambra de Granada o la Alcazaba de Málaga hubiera mantenido a ultranza los criterios conservacionistas de neutralidad o abstención, no habrían quedado más que escombros. Chueca justifica así la praxis de su maestro, manifestando que existe una necesidad de actuación sobre el monumento mediante la creación, y la restauración es en sí misma un acto de creación: "Torres Balbás creaba al mismo tiempo que restauraba". Pero la creación exige sensibilidad y res-peto hacia la obra

\footnotetext{
45 TORRES BALBÁS, L.: "La reparación de los monumentos antiguos en España”, op. cit

46 TORRES BALBÁS, L.: "La utilización de los monumentos antiguos”, en Arquitectura, III, julio 1920, pp. 179-181

47 Ibídem

48 CHUECA GOITIA, F.: “Torres Balbás, restaurador e historiador de la arquitectura”, en Sesión conmemorativa de la Fiesta Nacional del Libro Español (celebrada el día 30 de abril de 1982 en la Real Academia de la Historia), Madrid, Instituto de

España, 1982, pp. 26-27

49 Ibidem., p.29
} 


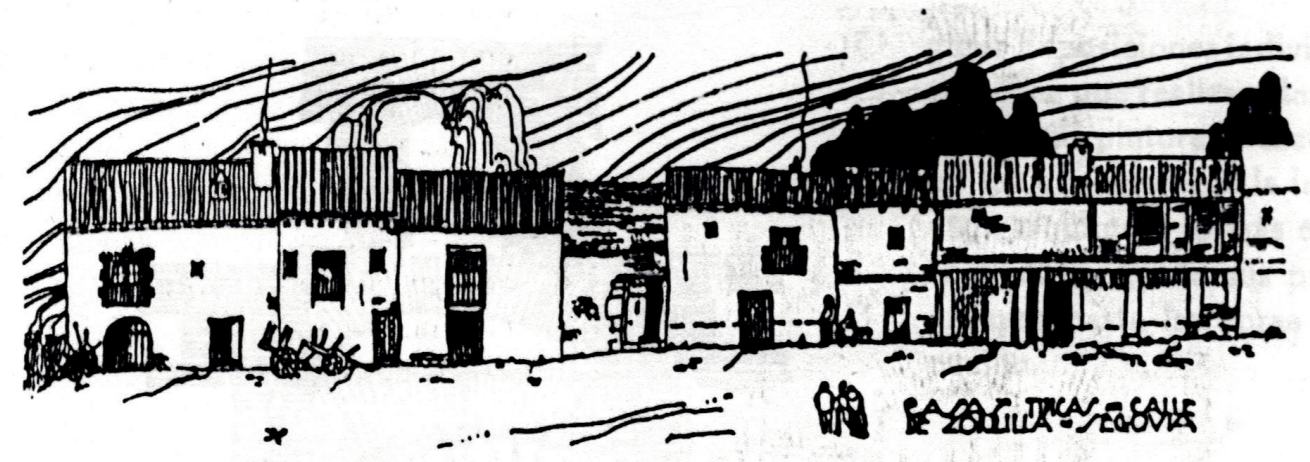

Fig.6 Arquitectura popular en Segoviä. Casas típicas en la calle de Zorrilla. Dibujos de García Mercadal y Rivas Eulate. Foto: TORRES BALBÁS, L.: "Glosas a un álbum de dibujos", Arquitectura, agosto 1922.

histórica, porque al restaurar se establece uno de los más sutiles vínculos entre presente y pasado. Vínculo que se dirige a cimentar los pilares de aprehensión del monumento por parte de la sociedad, por ello había que conferir al monumento tonos o matices ambientales: "la única manera de consolidar un edificio es terminarlo, es mantenerlo en pie, es completarlo de la manera que sea $(. . .)^{350}$.

\section{El valor de la historia en la praxis restauradora}

La actividad de Leopoldo Torres Balbás como historiador de la arquitectura fue enormemente rica y su preocupación por el Patrimonio añadida a su magnífica capacidad crítica, tuvo mucho que ver sin duda, con su habilidad para comprender y plasmar los acontecimientos históricos acaecidos en su país. La antología de publicaciones que recoge su obra refleja perfectamente una parcela de nuestra arquitectura desconocida casi por completo con anterioridad, insistiendo en la necesidad de su conocimiento. Ello le llevó a ser muy prolífico y a publicar en múltiples ocasiones artículos sobre esta cuestión ("Mientras labran los sillares" y "Ensayos: el tradicionalismo en la arquitectura española", ambos de 1918, en los que manifiesta abiertamente su crítica de la tradición hasta entonces operada: el estilo casticista o regionalista, que muchos veían como el paradigma del estilo arquitectónico español; "El aislamiento de nuestras catedrales" en 1919, y "La utilización de los monumentos antiguos" en 1920, todos ellos en Arquitectura). En los años veinte emprenderá una campaña de denuncia sobre el destino al que se estaba condenando el patrimonio arquitectónico español, en inminente peligro de desaparición. Postura crítica y militante de la que hará honor en numerosas ocasiones, especialmente cuando inaugure una sección sobre la arquitectura vernácula desconocida en la revista Arquitectura con el artículo "Rincones inéditos de la antigua arquitectura española" 51 . En dicho trabajo expone su impresión personal acerca de la arquitectura popular poco conocida hasta entonces, citando algunos ejemplos de edificaciones, muchas de ellas en ruina o en peligro de desaparición, incluyendo bosquejos y un breve comentario con las correspondientes noticias históricas vinculadas a los edificios contemplados o descubiertos en sus periplos.

${ }^{50}$ Ibidem., pp. 30-32

51 Vid. p. ej. TORRES BALBÁS, L.: "Rincones inéditos de la antigua arquitectura española. El caserío de Aguilar de Campoo (Palencia)" y "Rincones inéditos de la antigua arquitectura española. El Castillo de Lorca (Murcia)", ambos en Arquitectura, III, 1920, pp. 11-14. 
Asimismo realizó estudios historiográficos y comentarios críticos sobre las obras de otros autores, con lo que se patentiza un reconocimiento de las fuentes historiográficas como principal objetivo de la historia del arte aplicada a la tutela de la ciudad histórica. En la revista Al-Andalus construye una sección particular denominada "Crónica Arqueológica de la España Musulmana", en la que aborda el estilo hispanomusulmán presentándolo como crisol de influencias árabes, hispánicas, moriscas, mozárabes y mudéjares. En dicha sección difundirá durante casi tres décadas, hallazgos sobre las características de un período del arte español bastante desconocido hasta la fecha, relacionando magníficamente con su contexto histórico múltiples aspectos arquitectónicos, urbanísticos, decorativos, ornamentales y costumbristas.

Leopoldo Torres Balbás desempeñó su carrera a contracorriente en muchos momentos, luchando por abrir camino al conocimiento de la arquitectura popular y los monumentos desconocidos, a través de sus viajes por rincones inéditos de gran parte de la geografía española. Intentó con ello rescatar del olvido algunos edificios que no interesaban a priori, consciente de que era la única forma de salvarlos mediante su difusión y el acceso al conocimiento por parte de la sociedad. Durante los años veinte y treinta un tema de debate recurrente fue el de la reforma de los estudios de Arquitectura y la importancia concedida a la enseñanza de la Historia en las aulas universitarias ${ }^{52}$. Ello propició que el estudio del estilo regionalista motivase una revalorización de la arquitectura popular con gran trascendencia historiográfica $^{53}$. En esta primera época va gestando los dogmas de lo que llegará a ser su doctrina, escribiendo numerosos artículos sobre arquitectura histórica de las zonas visitadas en sus constantes viajes, como la región del centro y norte de España.

Resulta importante señalar, que en sus cuadernos de campo recoge innumerables notas sobre los monumentos que visitaba frecuentemente y dibujaba elementos como la distribución de plantas o detalles arquitectónicos como huecos, molduras, etc... Muchas veces incluía en sus publicaciones sus propios bocetos, o bien dibujos de alumnos o colegas a los que siempre atribuía la autoría correspondiente. En ocasiones realizaba viajes específicos de estudio para obtener documentación de los monumentos de una región, y aunque en esa época la transmisión de imágenes era precaria aún, la documentación gráfica le permitía efectuar un conocimiento empírico de la arquitectura histórica apropiado para iniciar su labor historiográfica ${ }^{54}$. La documentación obtenida directamente mediante anotaciones, fotografías o dibujos era posteriormente completada por un profundo conocimiento de la bibliografía existente. Las anotaciones y recopilación de doumentación indexada para sus artículos evidencian la importancia que el autor le concede a la labor historiográfica, constituyendo estos trabajos sobre arquitectura popular el primer estudio extensivo sobre esta materia en España, que abrirá una vía de estudio que será continuada por algunos de sus alumnos y seguidores ${ }^{55}$ : "Visité la Alhambra por primera vez guiado por él $[. .$.$] su dedicación era completa y su ilusionado afán admirable [...] debo a mi admirado$ colega los afanes profesionales y el estímulo para continuar los estudios, ya iniciados en Italia y España, sobre las arquitecturas mediterráneas" ${ }^{36}$.

Dotado de una férrea disciplina y un vasto bagaje intelectual, Leopoldo Torres Balbás desplegaba además, una implacable autocrítica sujeta a una fuerte voluntad de trabajo, lo que

52 Este tema ya fue planteado desde finales de la década de los diez, y de forma especial en el plan de 1914, hasta 1933, fecha en la que se aprobó un nuevo plan de estudios que permanecería en vigencia hasta 1957.

${ }^{53}$ VÁZQUEZ ASTORGA, M.: "La arquitectura vernácula como laboratorio de experimentación y vía de modernización para la arquitectura moderna”, en ARANDA BERNAL, A., OLLERO LOBATO, F., QUILES GARCÍA, F. y RODRÍGUEZ-VA-RO ROALES, R. [eds.]: Arquitectura Vernácula en el mundo ibérico, Actas del Congreso Internacional sobre Arquitectura Vernácula, CISAV (Carmona, 26-28 octubre, 2005), Sevilla, Universidad Pablo de Olavide, Ministerio de Educación y Cien-cia, 2007, p. 87.

54 TORRES BALBÁS, L.: "La vivienda popular en España", en Folklore y costumbres de España, III, Barcelona, 1933, pp. 139-502.

${ }_{55}$ MUÑOZ COSME, A.: La vida y obra... op. cit., p. 24.

56 GARCÍA MERCADAL, F.: "El recuerdo de Leopoldo Torres Balbás", en Sesión conmemorativa... op. cit., pp. 16-17. 


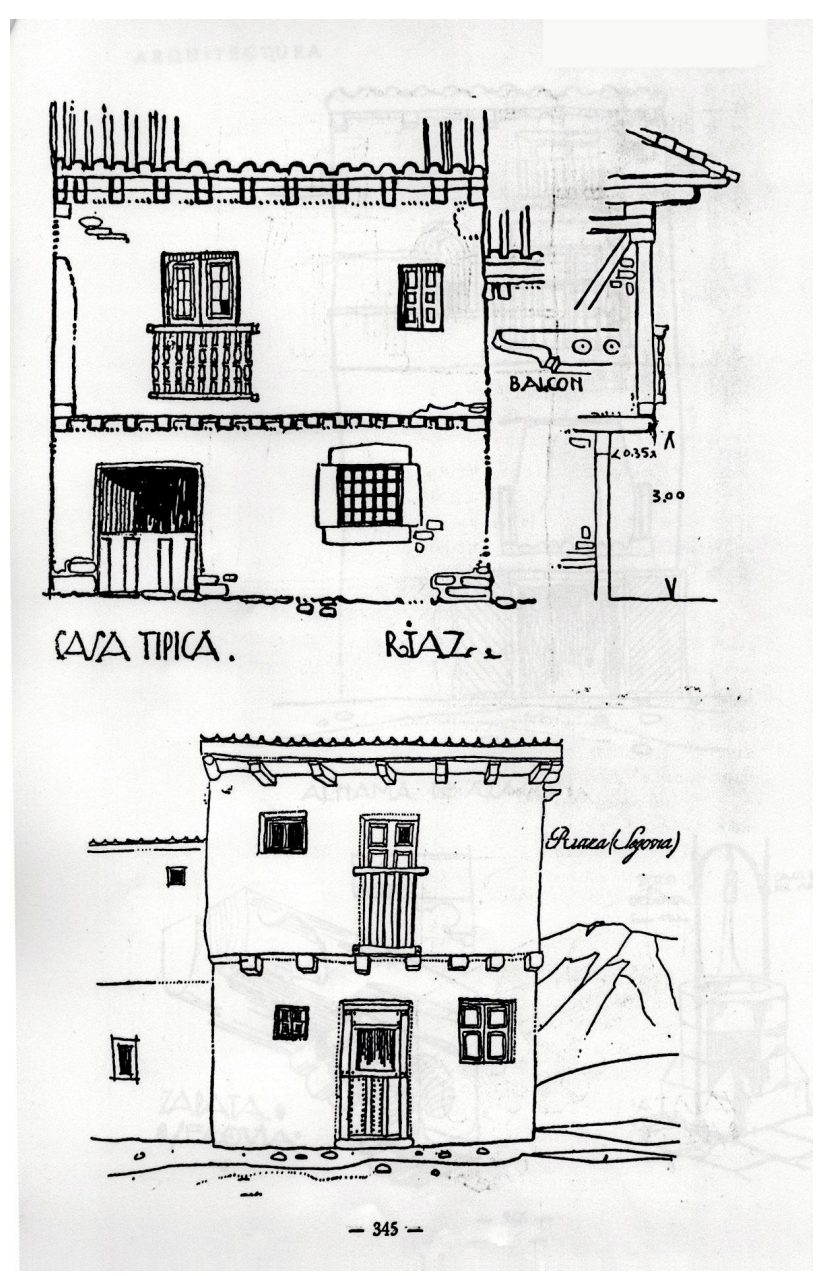

Fig.7 Arquitectura popular en Riaza (Segovia). Dibujos de García Mercadal y Rivas Eulate. Foto: "Glosas a un álbum de dibujos", cit.

le llevó a profundizar en el conocimiento de las cualidades que un arquitecto dedicado a la restauración arquitectónica debía poseer. Fue consciente de la falta de orientación que movía a los futuros arquitectos en su ejercicio profesional y opinaba al respecto: "El arquitecto no tiene más remedio que echar mano de un cierto número de formas y disposiciones para crear sus obras, puesto que es imposible inventarlas sacándolas de la nada [...] Si el arquitecto desconoce la tradición, si ignora la historia de su arte, fatalmente tomará las formas para sus creaciones de los edificios que contempla a su alrededor, y de aquellos otros que, por la fotografía o el dibujo, lleguen a sus manos. Es decir, que inevitablemente se inspirará en la tradición; pero en una tradición híbrida, de segunda o tercera mano. La historia de la arquitectura le ofrecerá, en cambio, un caudal de formas depuradas por obra de una lenta selección [...] Cuanta más historia arquitectónica se enseñe en nuestras escuelas, menos plagios de edificios antiguos se verán en las calles de nuestras ciudades [...] Aprovechemos la experiencia de nuestros antecesores, moviéndonos libremente dentro de la tradición $[\ldots]^{, 57}$.

La vinculación de Torres Balbás con ciertos ambientes intelectuales favorecerá que desde el núcleo de la Institución Libre de Enseñanza (ILE), su contacto con personalidades como Francisco Giner de los Ríos, Manuel Bartolomé Cossío, Manuel Gómez Moreno y el Marqués de Vega Inclán ${ }^{58}$ marquen irremisiblemente su carrera. La influencia institucionista

57 TORRES BALBÁS, L.: "La enseñanza de la historia...", op. cit., pp. 36-38

${ }^{58}$ El Marqués de Vega Inclán fue Comisario Regio de Turismo y llevó a cabo la restauración de los Reales Alcázares de Sevilla, edificio considerado por Torres Balbás como el primer ejemplo de restauración moderna realizado en España 
favorecerá que se exprese libremente, manifestando su inquietud por el modo tradicional de actuación respecto al patrimonio construido y delineando las bases de lo que será el concepto moderno de restauración de monumentos.

De este modo se elimina el componente sentimentalista en favor del rigor metodológico aplicado a la conservación monumental y se empieza a tomar conciencia de la importancia de los estudios históricos para el conocimiento del patrimonio. Torres Balbás opinaba que las huellas materiales subsistentes que debían combinarse con el estudio archivístico para hacer de la historia del arte algo dinámico, atendiendo al escenario-contexto donde cada elemento cobraba vital trascendencia. La ciudad integraba una serie de vestigios humildes, cotidianos y anónimos, que habían ido estratificándose durante centurias, aunque la mayor parte de la sociedad los desconociese. Precisamente, la compenetración entre los vestigios físicos y los sedimentos espirituales, las tradiciones y las costumbres de la sociedad era lo que contribuía a configurar su ambiente.

Aunque no lo afirme abiertamente, quizás adelanta la exigencia de la interdisciplinariedad cuando afirma que la civilización es un producto histórico que se ha desarrollado fundamentalmente en las ciudades, integrando una serie de "intrahistorias" que implican un grado de complejidad elevado y exigen un estudio específ ico para descifrar su mensaje. Un estudio que deberá necesariamente, ser abordado a través de la concurrencia de otras disciplinas que van más allá de la arquitectura: "La reconstrucción del escenario histórico español en toda su complejidad se impone cada vez con mayor apremio",59.

En todos y cada uno de los casos en que Torres Balbás estudia las posibilidades de una intervención restauradora se patentiza su sólido bagaje intelectual amparado en el rigor positivista. Siempre huía de elucubraciones teóricas o razonamientos filosóficos, buscando el firme puntal del dato histórico-documental, considerando aspectos como la concepción espacial o la influencia del medio sociológico en la creación arquitectónica. No obstante, nunca negó la posibilidad que determinadas teorías pudiesen nutrir la historia del arte, si bien con matices realistas, que es precisamente donde reside su esencial contribución ${ }^{60}$.

\section{Conclusiones}

En definitiva, Leopoldo Torres Balbás asumió nuevos criterios historiográficos en el estudio de la restauración arquitectónica. A través de sus investigaciones sobre la arquitectura histórica, concedió enorme importancia a las edificaciones menores que configuraban el entorno de los monumentos. Ello le llevó a inclinarse hacia una postura intermedia que conciliaba la conservación pura, con la utilización de diseños contemporáneos para afrontar las intervenciones de restauración, reparación o consolidación. Torres Balbás aprendió de Giovannoni, a situar los límites de la restauración en un punto heterodoxo y sincrético, contemplando diferentes modos de actuar, más dependientes de las necesidades prácticas de cada momento, que de los dogmatismos. Presumiblemente, gracias a sus contactos con el arquitecto italiano, empezó a considerarse en España la noción de ambiente, y se comenzaron a establecer medidas para la tutela de los entornos monumentales. Por otra parte, la influencia de la doctrina de Gustavo Giovannoni en el arquitecto español, se acusará en el cambio de rumbo que adquirirán las teorías sobre restauración en España.

${ }^{59}$ TORRES BALBÁS, L.: "Málaga como escenario histórico”, en Arquitectura, I, 187-188, julio-agosto, 1974,

${ }^{60}$ CHUECA GOITIA, F.: “Torres Balbás, restaurador e historiador...”, op. cit., pp. 25-26. 